\title{
Phenytoin and carbamazepine in trigeminal neuralgia: marketing-based versus evidence-based treatment
}

This article was published in the following Dove Press journal:

Journal of Pain Research

17 July 2017

Number of times this article has been viewed

\author{
Jan M Keppel Hesselink' \\ Michael E Schatman ${ }^{2,3}$ \\ 'Institute for Neuropathic Pain, \\ Bosch en Duin, the Netherlands; \\ ${ }^{2}$ Department of Public Health and \\ Community Medicine, Tufts University \\ School of Medicine, Boston, MA, USA; \\ ${ }^{3}$ Boston Pain Care, Waltham, MA, USA
}

Correspondence: Jan M Keppel Hesselink Institute for Neuropathic Pain, Spoorlaan 2a, 3735 MV, Bosch en Duin, The Netherlands Email jan@neuropathie.nu

\section{Introduction}

Most review articles support carbamazepine as a first-line pharmacotherapy for idiopathic trigeminal neuralgia. ${ }^{1-3}$ However, the empirical support for this recommendation is somewhat suspect. Phenytoin, as the prototype for all anticonvulsants, was already positioned as an analgesic compound 70 years ago. Since these initial findings, the data that have been gathered have supported the use of anticonvulsants as painkillers - from phenytoin up to and including more recent anticonvulsants such as gabapentin and pregabalin. Since 1942, a number of papers supported phenytoin's therapeutic effects in trigeminal neuralgia (Table 1). The introduction of carbamazepine in 1962 by Geigy shifted the interest of neurologists from phenytoin as a treatment for trigeminal neuralgia to carbamazepine, without sound scientific evidence. To date, no convincing randomized controlled trials (RCTs) have been published supporting the role of carbamazepine in trigeminal neuralgia, and we could not identify a single study comparing the effects of phenytoin with those of carbamazepine. Accordingly, phenytoin should probably be considered more often as a viable therapy for (treatmentresistant) trigeminal neuralgia.

\section{Trigeminal neuralgia: one of the first repositioning indications of phenytoin}

The exploration of phenytoin as an analgesic in neuralgic pain started 5 years after Putnam and Merritt identified the compound in 1937 as a treatment for convulsions. ${ }^{4}$ In 1942, a French otolaryngologist reported that $200-300 \mathrm{mg}$ phenytoin daily was effective in reducing pain in three patients suffering from trigeminal neuralgia. ${ }^{5}$ In 1944, a case study of a patient suffering from paroxysmal abdominal pain but responding well to phenytoin was presented; the pain attacks in his case were (perhaps erroneously) interpreted as a form of focal symptomatic epilepsy. ${ }^{6}$ The first indication in the field of pain that was explored intensively as a new indication (repositioning) for phenytoin was trigeminal neuralgia, most likely due to its paroxysmal character - reminiscent of epileptic discharges.

Based on some of these anecdotal reports of a possible analgesic role of phenytoin in the treatment of trigeminal neuralgia or "tic douloureux," phenytoin was identified as a putative anti-trigeminal pain therapy in a number of sources published as early as the $1950 \mathrm{~s}^{7-10}$ 
Table I Phenytoin in trigeminal neuralgia

\begin{tabular}{|c|c|c|c|c|}
\hline Reference & Subjects (n) & Study design & Dose & Non-responders \\
\hline Bergouignan (1942) ${ }^{5}$ & 3 & Open & $200-300 \mathrm{mg} /$ day & NR \\
\hline Moore $(1944)^{6}$ & I & Open & $200 \mathrm{mg} /$ day & NR \\
\hline Bergouignan and d'Aulnay $(195 \mathrm{I})^{\prime \prime}$ & 17 & Open & $300-600 \mathrm{mg} /$ day & 2 \\
\hline Jensen $(1954)^{14}$ & 45 & Open & $300-600 \mathrm{mg} /$ day & 5 \\
\hline Jensen $(1955)^{15}$ & 59 & Open & $300-600 \mathrm{mg} /$ day & 2 \\
\hline Winiker-Blanck (1955) ${ }^{19}$ & 27 & Open & 300-600 mg/day; 100 mg CD & 5 \\
\hline Ende $(1957)^{9}$ & 9 & Open & NR & NR \\
\hline Bergouignan $(1958)^{20}$ & 30 & Open & NR & 4 \\
\hline lannone et al $(1958)^{16}$ & 4 & Open & NR & 0 \\
\hline Kugelberg and Lindblom (1959) & 50 & Open & $3-5 \mathrm{mg} / \mathrm{kg}$ BW IV & NR \\
\hline Lamberts $(1959)^{22}$ & 30 & Open & $200-400 \mathrm{mg} /$ day & NR \\
\hline Braham and Saia $(1960)^{17}$ & 20 & Open & $300 \mathrm{mg} /$ day & 6 \\
\hline $\operatorname{Baxi}(|96|)^{23}$ & 15 & Open & & \\
\hline Lindblom $(196 \mid)^{24}$ & 30 & Open & $300-600 \mathrm{mg} /$ day & 13 \\
\hline Reeve $(1961)^{25}$ & 9 & Open & NR & NR \\
\hline Von Albert $(1987)^{26}$ & 12 & Open & $750 \mathrm{mg}$ IV followed by $200-400 \mathrm{mg} /$ day & NR \\
\hline Qi et al $(1995)^{18}$ & 36 & Randomized & NR & NR \\
\hline
\end{tabular}

Abbreviations: BW, body weight; CD, continuation dose; IV, intravenous; NR, not reported.

Bergouignan and d'Aulnay continued his work in this field and, in 1951, reported on the successful treatment with phenytoin in 17 patients suffering from trigeminal neuralgia (300-600 mg/day). There was only one non-responder in his study, and the clinical effect was reported to emerge quickly (within 24 hours). ${ }^{11}$

This indication was supported by electrophysiological studies of the inhibition of potentials in the trigeminal nerve by phenytoin. ${ }^{12}$ Evoked delayed potentials in the trigeminal nerve could be abolished by the intravenous administration of $50 \mathrm{mg}$ phenytoin. ${ }^{13}$

In 1954, a case series of 45 patients suffering from trigeminal neuralgia who were treated with 300-600 mg phenytoin/ day was published. Sixteen patients were full responders, 23 patients responded partially, and there were five nonresponders. ${ }^{14}$ In a follow-up study by the same author, 59 patients diagnosed with trigeminal neuralgia were treated with 300-600 mg phenytoin/day, and 57 became completely free of pain whereas only two were non-responders. ${ }^{15,16} \mathrm{~A}$ further series of 20 patients were reported in 1960, with symptomatic relief reported by 14 of the subjects. ${ }^{17}$

At the National Workshop of Clinical Use of Phenytoin in Chengdu, People's Republic of China, in 1995, the authors presented the results of 36 patients with trigeminal neuralgia, who had been randomly assigned to three treatment groups: phenytoin (17 patients); carbamazepine (11 patients); and combined phenytoin and carbamazepine (8 patients). After 4 weeks of treatment, the effects of phenytoin and carbamazepine were comparable ( $82.35 \%$ and $81.81 \%$ responders, respectively), whereas combination treatment was superior. ${ }^{18}$
All studies were published between 1942 and 1995; after 1995, we could not identify any outcome study evaluating phenytoin in trigeminal neuralgia.

In 2012, the Cochrane collaboration could not identify any RCTs of phenytoin in neuropathic pain. ${ }^{27}$

\section{The entrance of Geigy 32883: carbamazepine}

In 1958, the chemist Walter Schindler first described a number of N-heterocyclic compounds in a patent, one being carbamazepine; a year later, a second patent related to this matter was filed by Geigy. The inventors were Schindler and Charles Gansser. Initially, the compound was known as Geigy 32883 and, in 1962, G32883 was registered for the treatment of trigeminal neuralgia.

In 1962, the first clinical article was published in The Lancet by Blom from the University of Uppsala, Sweden. ${ }^{28}$ He directly linked the general clinical experiences known up to that point for phenytoin to the effects of the new Geigy drug in his own hands. Blom stated: "It soon became evident that the effect was very good - probably better than that of diphenylhydantoin." (p.839) This conclusion was based only on his experience with 11 patients in an open study, yet it seemingly legitimized the new Geigy drug (which was patent protected) as a superior treatment for trigeminal neuralgia. Seven of these 11 patients were previously treated with phenytoin: there were two non-responders on phenytoin, both responding to carbamazepine; two responders on phenytoin became non-responders after 2 years and subsequently responded to carbamazepine; two patients could not tolerate 
phenytoin; and two responded as well on phenytoin as on carbamazepine. Plasma levels were not measured. Blom published a comparable paper in the Archives of Neurology, and other uncontrolled case studies followed in the same period. ${ }^{29-33}$ The initial placebo controlled study was reported in 1966 by the hand of clinicians from Guy's Hospital, London (UK), who included 77 patients and analyzed the results of 70 patients, excluding seven dropouts. ${ }^{34}$ Carbamazepine was better compared to placebo (no statistics), but half of all patients experienced at least one side effect on carbamazepine compared to only $24 \%$ on a placebo.

In 1995, a systematic review was published in the $B M J$ covering all RCTs related to anticonvulsants prescribed for analgesia. ${ }^{35}$ Since 1995, no new RCTs have been indexed in this field in PubMed. The authors were able to identify only two RCTs on the efficacy of carbamazepine in trigeminal neuralgia. These RCTs both followed a crossover design and recruited only 27 patients and 20 patients, respectively, gauging outcomes after 5 days of treatment and 14 days, respectively. All other studies conducted were not randomized controlled studies. The authors also identified only three comparator studies wherein carbamazepine was compared to tizanidine, tocainide, and pimozide, but none comparing carbamazepine to phenytoin.

Most recent review articles state that first-line pharmacotherapy for idiopathic trigeminal neuralgia should be carbamazepine. ${ }^{36}$ However, given our review of the limited literature, the alternative statement supporting phenytoin as the first choice seems equally valid.

\section{Commercial and IP reasons for shifting attention from phenytoin to carbamazepine}

Interestingly, it was only after Geigy became the official developer of carbamazepine in the 1960s as pharmacotherapy for idiopathic trigeminal neuralgia that clinicians began to resort to the drug as their first choice for this indication, irrespective of the lack of convincing evidence of its superiority to phenytoin. Phenytoin, however, unlike carbamazepine, was not patent protected. It is extremely likely that carbamazepine's patent protection in conjunction with aggressive marketing by Geigy explains why the research and clinical focus shifted from phenytoin to carbamazepine. To date, there are still no convincing RCTs proving the superiority of carbamazepine over phenytoin in trigeminal neuralgia. There is as much evidence supporting phenytoin as the first choice for the treatment of trigeminal neuralgia rather than carbamazepine. Furthermore, given the complex side effects of carbamazepine, one might even argue for phenytoin as the rational first choice.

In 1975, in a JAMA article on "new uses of phenytoin" the authors concluded in line with our arguments: "controlled studies have not demonstrated conclusively the efficacy of either phenytoin or carbamazepine, and there is no good evidence to support the use of either or both agents." ${ }^{37}$

From an ethical perspective, we struggle with this. To substitute patent protection and aggressive marketing for scientific evidence of superiority or even non-inferiority potentially puts our patients at risk for oligoanalgesia in the name of corporate profits. Although we have highlighted the unfortunate histories of phenytoin and carbamazepine, these are certainly not the only pain medications with regard to which the wool has been pulled over the eyes of unsuspecting prescribers and their patients. Our hope is that clinicians will accept this editorial as a warning to familiarize themselves with the empirical data supporting the prescription of one drug over another, as our cautionary tale demonstrates that "the next great thing" is not necessarily all that great.

\section{Disclosure}

The authors report no conflicts of interest in this work.

\section{References}

1. Reddy GD, Viswanathan A. Trigeminal and glossopharyngeal neuralgia. Neurol Clin. 2014;32(2):539-552.

2. Zakrzewska JM, Linskey ME. Trigeminal neuralgia. BMJ. 2014;348:g474.

3. Cruccu G. Trigeminal neuralgia. Continuum (Minneap Minn). 2017;23 (2, Selected Topics in Outpatient Neurology):396-420.

4. Putnam TJ, Merritt HH. Experimental determination of the anticonvulsant properties of some phenyl derivatives. Science. 1937;85(2213): 525-526.

5. Bergouignan M. Successful cure of essential facial neuralgias by sodium diphenylhydantoinate. Rev Laryngol Otol Rhinol (Bord). 1942;63:34-41.

6. Moore MT. Paroxysmal abdominal pain: a form of focal symptomatic epilepsy. JAMA. 1944;124(9):561-563.

7. Kubanyi E. Trigeminusneuralgie: Differentialdiagnose und Therapie der Gesichtsschmerzen. [Trigeminal neuralgia: Differential diagnosis and therapy of facial pain]. Vienna: Urban \& Schwarzenberg; 1956. German.

8. Berczeller E, Szecsody E. Behandlung der Neuralgien mit antikonvulsiven Mitteln. [Treatment of neuralgia with anticonvulsive funds]. Nervenarzt. 1956;27(8):369-370. German.

9. Ende M. Diphenylhydantoin in tic douloureux and atypical facial pain. Va Med Mon (1918). 1957;84(7):358-359.

10. Sperling E, Stender A. "Tic douloureux" und Gesichtsschmerz. Therapeutische und pathogenetische Betrachtungen ["Tic douloureux" and facial pain; therapeutic and pathogenetic comments]. Dtsch Z Nervenheilkd. 1955;173(2):161-183. German [with English abstract].

11. Bergouignan M, d'Aulnay N. Effects of sodium diphenylhydantoin in essential trigeminal neuralgia. Rev Otoneuroopthal (Paris). 1951;23:427-431.

12. King RB, Meagher JN. Studies of trigeminal nerve potentials. J Neurosurg. 1955;12(4):393-402. 
13. King RB, Barnett JC. Studies of trigeminal nerve potentials; overreaction to tactile facial stimulation in acute laboratory preparations. J Neurosurg. 1957;14(6):617-627.

14. Jensen HP. The treatment of trigeminal neuralgia with diphenylhydantoin. [Therapy of trigeminal neuralgia with diphenylhydantoin]. Arztl Wochensch. 1954;9(5):105-108. Undetermined language [with English abstract].

15. Jensen HP. The treatment of trigeminal neuralgia with diphenylhydantoin. Therapiewoche, $5: 345,1955$, quoted in Dreyfus J. The story of a remarkable medicine, New York: Lattern Books; 1996:363.

16. Iannone A, Baker AB, Morrell F. Dilantin in the treatment of trigeminal neuralgia. Neurology. 1958;8(2):126-128.

17. Braham J, Saia A. Phenytoin in the treatment of trigeminal and other neuralgias. Lancet. 1960;276(7156):892-893.

18. Qi L, Liu C, Huang M. A double-blind study of the effect of phenytoin on trigeminal neuralgia, presented at the National Workshop of Clinical Use of Phenytoin, Chengdu, China, 1995. Available from: http:// www.remarkablemedicine.com/Clinical/clinicaluses/paintreatment/ trigeminal.html. Accessed February 20, 2017.

19. Winiker-Blanck E. [On the diphenylhydantoin therapy of trigeminal neuralgia]. Dtsch Stomatol. 1955;5(6):321-322.

20. Bergouignan M. Fifteen years of therapeutic trials in essential trigeminal neuralgia: the place of diphenylhydantoin and its derivatives. Rev Neural (Paris). 1958;98:414-416

21. Kugelberg E, Lindblom U. The mechanism of the pain in trigeminal neuralgia. J Neurol Neurosurg Psychiatry. 1959;22(1):36-43.

22. Lamberts in the Journal of Michigan State Medical Society, 1959, quoted in: Smith BH, Bogoch S, Dreyfus J. The Broad Range of Clinical Use of Phenytoin; Bio-electrical Modulator; Bibliography and Review. New York: Dreyfus Medical Foundation; 1988.

23. Baxi, 1961, quoted in: Smith BH, Bogoch S, Dreyfus J. The Broad Range of Clinical use of Phenytoin. New York: Dreyfus Medical Foundation; 1988.

24. Lindblom U. Diphenylhydantoin for trigeminal neuralgia. Svenska läkartidningen. 1961;58:3186-3191. Swedish [with English abstract].
25. Reeve HS. Phenytoin in the treatment of trigeminal neuralgia. Lancet. 1961;277(7173):404.

26. Von Albert, 1987, quoted in: Smith BH, Bogoch S, Dreyfus J. The Broad Range of Clinical use of Phenytoin. New York: Dreyfus Medical Foundation; 1988.

27. Birse F, Derry S, Moore RA. Phenytoin for neuropathic pain and fibromyalgia in adults. Cochrane Database Syst Rev. 2012;(5): CD009485.

28. Blom S. Trigeminal neuralgia: its treatment with a new anticonvulsant drug (G-32883). Lancet. 1962;1(7234):839-840.

29. Blom S. Tic douloureux treated with new anticonvulsant; experiences with G 32883. Arch Neurol. 1963;9:285-290.

30. Largé M. Klinische Erfahrungen mit einem neuen Antiepileptikum, Tegretol (G 32883) mit besonderer Wirkung auf die epileptische Wesensveränderung. [Clinical experience with a new antiepileptic, Tegretol (G 32883) with particular effect on the epileptic Personality changes]. Schweiz Med Wschr. 1963;93:1042-1047. German.

31. Bonduelle M, Sallou C. Tegretol (Geigy). Therapie. 1963;18: 543-548.

32. Spillane JD. The treatment of trigeminal neuralgia with 'Tegretol'. In Proceedings of the Association British Neurologists, Harrogate, April 1963. Quoted in J Neurol Neurosurg Psychiatry. 1966;29:267.

33. Taylor JC. Trigeminal neuralgia treated with G.32883. J Neurol Neurosurg Psychiatry. 1963;26:553-554.

34. Campbell FG, Graham JG, Zilkha KJ. Clinical trial of carbazepine (tegretol) in trigeminal neuralgia. J Neurol Neurosurg Psychiatry. 1966;29(3):265-267.

35. McQuay H, Carroll D, Jadad AR, Wiffen P, Moore A. Anticonvulsant drugs for management of pain: a systematic review. $B M J$. 1995;311(7012):1047-1052.

36. Obermann M. Treatment options in trigeminal neuralgia. Ther Adv Neurol Disord. 2010;3(2):107-115.

37. Walson P, Trinca C, Bressler R. New uses for phenytoin. JAMA. 1975; 233(13):1385-1389.
Journal of Pain Research

\section{Publish your work in this journal}

The Journal of Pain Research is an international, peer reviewed, open access, online journal that welcomes laboratory and clinical findings in the fields of pain research and the prevention and management of pain. Original research, reviews, symposium reports, hypothesis formation and commentaries are all considered for publication.

\section{Dovepress}

The manuscript management system is completely online and includes a very quick and fair peer-review system, which is all easy to use. Visit http://www.dovepress.com/testimonials.php to read real quotes from published authors. 